\title{
Embracing Dissonant Voices In English Classrooms
}

\author{
Ya-huei Wang, Chung-Shan Medical University, Taiwan
}

\begin{abstract}
The purpose of this study is to determine whether a pedagogy grounded in dialogical ideals has the potential to empower students to make changes in English classroom interaction. The study first scrutinized the traditional "banking" educational system in English classrooms in which students were passive learners to realize students' silence and powerlessness in classrooms. Then, after realizing students' silence and resistance in traditional English classrooms, with a vision of social change, the researcher proposed the dialogical interaction pedagogy to the English class to challenge the traditional view of authority and power, with an eye to exposing how dominant education was constructed through language and discourse. Unlike the traditional teaching-learning structures in which instructors act as authorities and subjects, and students act as objects and receivers, the dialogical English classroom, adapted from traditional classroom hierarchy structures, is a double-voiced or even multiple-voiced English learning environment in which both the teacher and students work together to overcome the estrangement and alienation that have long become the norm in the contemporary English classroom system.
\end{abstract}

Keywords: Banking education, dialogical interaction

\section{INTRODUCTION}

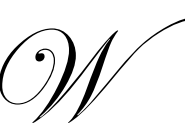

ith the progress of global economy, it is essential that students acquire communication skills in English, a common international language, in order to compete and survive in the twenty-first century (Chen, Warden, \& Chang, 2006). Taiwan is a geographically isolated island in Asia with an official language of Mandarin Chinese. Typically, in Taiwanese learning environment, English language learners do not have many chances to use English, not to mention to speak or communicate with teachers, classmates, or even native English speakers (Cifuentes \& Shih, 2001). Besides, with the pressure of entrance examinations, English teachers prefer grammatical approaches to oral communication practices, which is the cause of students' inability to speak English confidently (Yong \& Chu, 1993). In this kind of English lecturing instruction, students do not acquire enough English communicative abilities necessary for the era of globalization and information technology (Butler \& Iino, 2005; Chen, 2002).

In Taiwan, the class is always in an authoritarian atmosphere. In this authoritarian atmosphere, teaching and learning are linear and information flows primarily from teachers to students (Rendon, 2005). That is, the whole class instruction is teacher-centered (Jensen, 2000). In the traditional Chinese teacher-centered instruction, students are required to sit quietly in rows and passively copy down what the teacher lectures. Classroom engaging in this form of instruction includes a familiar routine: checking answers from the previous day's assignments, working some of the homework problems on the board, presenting new materials with examples, and assigning seatwork. The traditional teacher-centered instruction favors "teacher talk" over "student talk;" the teacher directs instruction to the whole class rather than works with small groups of students or with individual students (Cuban, 1984; Presmeg, 1998). Hence, students in the traditional classroom, being viewed as isolated objects, do not see and cannot develop their potential outside the classroom.

Obviously, this dominating classroom structure is a hierarchical, top-down structure. In this structure, teachers serve as professional authority and consider students ignorant. Students passively receive what teachers know and what they intend to lecture in class; all students can do is listening, taking notes, memorizing, and in 
suitable times, giving the lecture back to teachers in order to get good grades. Teachers, the main controller of the knowledge transmission during the learning process, would deliberately keep a distance from their students. Freire (1973) has critiqued this kind of separation between teachers and students as well as between teaching and learning, calling this kind of one-way instruction system the "banking model of education," in which teachers distance themselves from students, and "deposit" their knowledge in the classroom.

According to Freire (1973), in the "banking" education system, there is an unequal relationship which undermines any attempt to generate an atmosphere of inquiry and genuine dialogue because teachers serve as the authoritative power to assess and pass the knowledge to students. In this banking education system, a one-way instruction system, teachers teach while students are taught. Teachers know everything, while students know nothing. Teachers think, while students are thought about. Teachers talk, while students can only listen meekly. Teachers discipline, while students are disciplined. Teachers choose and enforce their choice, while students can only comply. Teachers act, while students can only have the illusion of acting through the action of teachers.

To sum up, in the traditional banking education system, teachers confuse the authority of knowledge with their own professional authority, which is set in opposition to the freedom of students. Teachers serve as the subjects of the learning process, while students as the objects. Teachers serve as knowledge producers, while students serve as knowledge consumers. Knowledge becomes the goods being deposited by the depositor (teachers) to the depositories (students). Accepting the passive roles imposed to them, in order to adapt to teachers' teaching styles, all students can do is making their effort to keep silent and follow the authority's instructions. Without doubt, this traditional classroom instruction would minimize students' creative power and reflection ability.

\section{THE APPLICATION AND IMPLEMENTATION OF DIALOGICAL INTERACTION INSTRUCTION TO ENGLISH CLASS}

The purpose of this study is to determine whether a pedagogy grounded in dialogical ideals has the potential to empower students to make changes in English classroom interaction. The study first scrutinized the traditional "banking" educational system in English classrooms in which students are passive learners to realize students' silence and powerlessness in classrooms. Then, after realizing students' silence and resistance in traditional English classrooms, with a vision of social change, the researcher proposed the dialogical interaction instruction to the English class to challenge the traditional view of authority and power, with an eye to exposing how dominant education was constructed through language and discourse. Unlike the traditional teaching-learning structures in which instructors act as authorities and subjects, and students act as objects and receivers, the dialogical English classroom, adapted from traditional classroom hierarchy structures, is a double-voiced or even multiple-voiced English learning environment in which both the teacher and students work together to overcome the estrangement and alienation that have long become the norm in the contemporary English education system.

It is believed that the development of an egalitarian classroom atmosphere can be best accomplished through the use of dialogues. According to Freire (1970), dialogical interaction between students and the teacher is the key to liberating education. However, in a traditional English class, the instruction is used as a tool for the reproduction of the existing professional authority, knowledge, and societal power systems in which single-voice discourses are spoken. (Freire, 1973; hooks, 1989; Maher \& Tetreault, 1994). In this single-voiced English classroom, the teacher adheres to their own viewpoints without taking conflicting voices into consideration. However, in the dialogical interaction English classroom, it becomes possible to develop "double-voiced" or "multiple-voiced" discourses, in which both the teacher and students would not adhere to their own viewpoints but intend to perceive different stances and different voices. Hence, through dialogical interaction with others in the classroom, both the teacher and students would keep developing and revising their own views. The following methods and tools are proposed to initiate and facilitate the application and implementation of the dialogical interaction instruction.

\section{Creating a Comfortable Learning Environment}

This dialogical interaction English classroom intends to create a comfortable learning environment in which students are willing to participate in class interaction. In this classroom, the teacher should first ensure the 
psychological and emotional safety of their students in order to let students willingly give their voices. Besides, the teacher should ensure that this is a non-competitive class in which all students have not only equal opportunity to speak out or talk back about their experiences but also have equal power in influencing decision-making both inside and outside of the classroom in which high levels of trust, personal commitment, and democratic dialogue are possible.

\section{Empowering Students}

This dialogical interaction English classroom intends to interrupt the reinforced patriarchal dominance classroom and give power to all students in the classroom. In order to empower students, dialogical interaction English classroom intends to interrupt the reinforced patriarchal dominance classroom and gives power to all students in the classroom. Instead of seeking a reversal of the patriarchal power structure, the dialogical interaction classroom seeks to empower and to give voice to students. In order to foster the empowering environment, sometimes role models are adopted to help these students build up their confidence.

\section{Listening to Students' Voices}

In order to empower students to find their own voices in the classroom, teachers should engage in a purposeful process to listen to the voices of their students, either speaking voices or silent voices. While being encouraged to emerge their "authentic voices" to public space, students are seen to make themselves visible and have a chance to define themselves as authors of their own world. Through giving voices, students can construct knowledge and give self-definitions which are oppositional to those definitions constructed by others. Such self-definition presumably gives students identities and political positions from which to act as agents of social change.

\section{Initiating Dialogical Interaction}

An egalitarian classroom can best be accomplished through the use of dialogical interaction, for the dialogue between students and the teacher is the key to lead to liberating education (Freire, 1970). Through dialogues, students are given an opportunity to have their voices heard. The essence of the dialogical interaction is to be open to multiple viewpoints through communication and interaction. Hence, it is required that both the teacher and students be open and willing to listen reflectively to alternative views.

In summary, through creating a comfortable learning environment, empowering students, listening to students' voices, and initiating dialogical interaction, the researcher intends to create an egalitarian learning environment in which students can speak for themselves. Through language and discourse in class, students may create multiple presentations of reality constituted in social structure. Most importantly, with emphasis on the dialogical interaction, the teacher would keep remind himself/herself of appreciating the differences among students, such as racial difference, gender difference, skill difference, etc. and by celebrating differences, both the teacher and students may repudiate common values and goals. While implementing the dialogical interaction instruction, the teacher is responsible for nurturing and embracing differences in the classroom, creating an atmosphere in which students of different backgrounds would feel comfortable in expressing their opinions from multiple perspectives.

\section{METHODOLOGY}

In this research, two homogeneous and normally distributed classes were chosen as the experimental group and the control group. By the flipping of the coin, the class of B1-A was chosen as the experimental group, while the class of B1-B was regarded as the control group. A total of ninety-one freshmen at one university in central Taiwan participated in this study, 45 participants in the control group and 46 in the experimental group. The participants were the students of business administration department, who had studied English for at least six years starting in junior high school. Upon graduation, these students were expected to become professionalized in the field knowledge of business administration. The experiment was implemented over 16 weeks for two hours a week in 2009. The difference between the experimental group and control group was the manipulation of the dialogical interaction instruction. The students participated in the control group were mainly instructed with the traditional 
teaching methods, here the grammar translation and lecturing methods. In this classroom, the teacher intended to analyze the grammatical construction of every single sentence or single phrase and expected the students to know the meaning of every single word. Hence, the whole instruction was limited to an activity performed by an authority serving as information provider, who stood in the front of a classroom and verbally distributed factual information to students, i.e. lecturing.

Prior to the experiment, the pretest on English learning achievement test was administered to both groups, and the test results were collected, analyzed and compared immediately by the researcher. It was found that both groups were at about the same proficiency level. After 16 weeks of instruction, the learning achievement post-test was administered to both the experimental group and the control group. Moreover, the initial and subsequent open-ended, semi-structured interviews were used to guarantee rich and pertinent information so that all class interaction and student responses could be analyzed and interpreted. Subsequent students' interviews allowed participants to further express their opinions and generated the depth of their personal perceptions.

\section{RESULTS AND DISCUSSION}

Through creating a comfortable learning environment, empowering students, listening to students' voices, and initiating dialogical interaction, the research results showed that the dialogical interaction English class brought a positive effect on students' English achievement. The results show that all the mean scores of the experimental group are higher than those of the control group. As for the comparison between both groups in terms of percentage rate, based on the mean scores on the English achievement post-test, it is shown that the dialogical interaction instruction has positive effects on the students' English learning achievements. That is, the participants receiving the dialogical interaction instruction outperform those receiving the traditional English instruction. As mentioned, in the English achievement pre-test, there were no differences between the control group and the experimental group in terms of listening, vocabulary, grammar, reading, and overall section. After the treatment, the post-test scores in both groups were examined. In the listening section, the mean of the experimental group is $17.20 \%$ higher than the mean of the control group. As for the vocabulary section, the mean of the experimental group is $21.52 \%$ higher than the mean of the control group. As for the grammar section, the mean of the experimental group is $19.18 \%$ higher than the mean of the control group. As for the reading section, the mean of the experimental group is $21.18 \%$ higher than the mean of the control group. Above all, as for the overall performance, the mean of the experimental group is $19.55 \%$ higher than the mean of the control group. Obviously, the participants receiving the dialogical interaction instruction outperform those receiving the traditional English instruction. The comparison between the two groups is shown in the following Table 1.

Table 1: Comparison between the both groups based on the English achievement post-test

\begin{tabular}{cccccc}
\hline & Listening & Vocabulary & Grammar & Reading & Overall \\
\hline Post-test Experimental group & 24.87 & 17.62 & 13.98 & 18.82 & 75.29 \\
Post-test Control group & 21.22 & 14.50 & 11.73 & 15.53 & 62.98 \\
$x \%$ & $17.20 \%$ & $21.52 \%$ & $19.18 \%$ & $21.18 \%$ & $19.55 \%$ \\
\hline
\end{tabular}

$x \%=\frac{\text { The mean of experiment al group }- \text { The mean of control group }}{\text { The mean of control group }}$

In conclusion, from the data shown in Table 1 and 2, it is clearly demonstrated that the students receiving the dialogical interaction English class outperform those receiving the traditional English instruction.

To triangulate the quantitative data obtained in the post-experimental dialogical interaction English class, student interviews were adopted to explore the students' personal feelings and individual reflection about the dialogical interaction English class. Based on the excerpts of the interviews, most students in the dialogical interaction class revealed that they enjoyed attending this English class, for they could interact much more frequently with the teacher as well as with the students.

- $\quad$ I like to listen to my classmates' voices and share my opinions with them. (S2) 
- In this class, we have more time to share our experience with the teacher and the classmates without being afraid of being criticized or laughed at. The teacher said that, "All of us have the right to express our opinions, and we ourselves should appreciate our own opinions." (S3)

In addition, it was found that most interviewees felt pleasant about learning English in the dialogical interaction English classroom. Also, they liked the feeling of being respected and appreciated.

- $\quad$ I like the feeling of being appreciated and respected. Before, I always fell asleep in English classes. Now, I feel so energetic, for I have more chances to speak up in the class, and the teacher would listen to my opinions attentively.

- With face-to-face oral interaction with the teacher and the classmates, the whole class becomes more interesting. It's nice to listen to many different voices.

- $\quad$ This class gives us a chance to listen to many students' talk patiently and attentively. I really enjoy their opinions and it is nice to hear diverse voices in this class.

- In this pleasant and unthreatening English learning environment, I feel it is quite comfortable to express my opinions. Right now, I dare to speak up for my opinions in the class. I like the feeling of being appreciated and respected.

From the above interviews, it is demonstrated that the dialogical interaction instruction has a positive effect on the students' English learning outcome, for the students have more time and opportunities to express their opinions and to interact with their classmates as well as the teacher. Unlike the traditional English class in which students are required to sit quietly to listen to the teacher's lecture, the students here can speak up and express their opinions without being afraid of being criticized or ridiculed. Therefore, the students enjoy sharing their feeling with their classmates and the teacher. Hence it can be implied that the dialogical interaction English class fosters students' communication and interaction with their classmates as well as the teacher.

Typically in the traditional authoritarian Chinese classroom, the teacher is in complete control of the class instruction while transmitting knowledge to students who can only listen quietly and attentively. Students' talk back in the class would be interpreted as an insult to the elders (Hong, Lawrenz, \& Veach, 2005). When in class, teachers are regarded as the sole authority in terms of their professional knowledge and expertise, a hierarchical relationship arises between teachers and their students. Besides, being rooted in collective-oriented culture, unlike Western students, who are adventurous in nature and actively confronted with external environment, Chinese and Taiwanese students care much about not only losing their face but also their family's face (Bond \& Huwang, 1987). Hence, caring too much about "face" problems, Students in Taiwan dare not to express their opinions in class but are adapted to passively accept teachers' instruction. Otherwise, they would be thought that they are students without manners (Canada \& Pringle 1995). Therefore, in order to be considered elegant and well-raised, students in Taiwan would like to keep silent and voiceless in order to leave others' good impression.

However, with the application of dialogical interaction instruction, students can actively get involved in their learning process and in some way control over their learning process. Besides, they can get involved in dialogical interaction with an eye to shaping the content of what is to be learned (Fiere, 1970 \& 1985). By downplaying the authority of the teacher, students can openly share and communicate with the teacher and their classmates and actively get involved in the knowledge construction. Hence, there is not a sole authority but multiple authorities, for authority can be developed from a variety of sources, especially from students' prerequisite knowledge and their life experiences. The promotion of multiple authorities allows different dynamics and different voices to speak out in the classroom. Also, through the dynamic interaction, a liberating learning environment is created in which authorities are constantly shifting from students to the teacher and then from the teacher to students (Lelwica, 1999). Therefore, the knowledge and the "truth" is always in the process, waiting to be shared, waiting to be enjoyed, and waiting to be freed.

\section{CONCLUSION AND PEDAGOGICAL IMPLICATIONS}

Learning is by no means a passive activity in which instructors give (teach) and students take (learn). On the contrary, the teaching-learning relationship should be in an interactive relationship. The study intends to 
investigate that whether a dialogical interaction class has the potential to bring positive effects on English learning outcome in terms of the English learning achievement. The results of English language achievement tests not only have the purpose to assess and evaluate how successful students have been in achieving their learning objectives but also could help students create positive learning attitude toward the class (Madsen, 1983; McNamara, 20000). Besides, with the results of English language achievement test, teachers can adjust and correct their teaching method to maximize students' learning outcome.

The usefulness of the dialogical interaction English classroom lies in its egalitarianism, democracy, and empowerment to students. Through face-to-face and verbal dialogical interaction, both teachers and students need to learn to listen to and to interact with others in a respectful way. When students propose their viewpoints, they empower themselves some certain freedom to engage dialogically with one another. As Freire (1970) said that through dialogical interaction, the hierarchical teacher-student relationship would cease to exist, and the teacher-student relationship is much more like a democratic co-learning relationship. Therefore, this dialogical interaction becomes a way of sharing power and opening communication between teachers and students. Besides, through dialogue communication, students are transformed from passive knowledge-consumers into active knowledge producers.

Based on the findings derived from this study, with the application of democratic dialogical interaction to the English class, the students instructed in the dialogical interaction display better learning outcome than those exposed to the traditional instruction. Based on the results of the English achievement post-test, in the listening section, the mean of the experimental group is $17.20 \%$ higher than the mean of the control group. In the vocabulary section, the mean of the experimental group is $21.52 \%$ higher than the mean of the control group. In the grammar section, the mean of the experimental group is $19.18 \%$ higher than the mean of the control group. In the reading section, the mean of the experimental group is $21.18 \%$ higher than the mean of the control group. Above all, in the overall performance, the mean of the experimental group is $19.55 \%$ higher than the mean of the control group. Obviously, the participants receiving the dialogical interaction instruction outperform those receiving the traditional English instruction. Also, from the interviews, the students under the dialogical interaction instruction feel satisfied with their English class, for they are offered the chance to speak up for their opinions and have the right to defend their stances as much as they could.

Aiming to foster an English learning environment in which dialogical interaction is emphasized, this paper intends to provide an alternative for English teachers to build up a class fostering students' communication and further an interactive relationship between teachers and students. While implementing the dialogical interaction instruction, teachers should always remind themselves to ensure the psychological and emotional safety of their students. Most importantly, in the dialogical interaction English classroom, teachers should always remind themselves that they should give up some aspects of authority coming with their positions, such as controlling over discussion and dominating the class.

\section{AUTHOR INFORMATION}

Ya-huei Wang is an Associate Professor at Chung-Shan Medical University. She received her PhD in education from National Changhwa University of Education, Taiwan. Her research interests include applying effective motivational strategies to class instruction, learning strategies, Chinese culture, and technical-vocational education. Her papers have been published by Expert Systems with Applications, the British Journal of Educational Technology, the Journal of Management in Education, the Asian EFL Journal Quarterly, the European Journal of Social Science, etc.

\section{REFERENCES}

1. Bond, M. H., \& Hwang, K. (1987). Research in Social Psychology: Interpersonal Processes. In M. H. Bond (Ed.), The psychology of the Chinese people (pp. 241-266). Oxford, UK: Oxford University Press.

2. Butler, Y. G.., \& Iino, M. (2005). Current Japanese reforms in English language education: The 2003

'Action Plan.' Language Planning, 4(1), 25-45. 
3. Chen, J. F., Warden, C. A., \& Chang, H. T. (2006). In English a brand: The impact of English language learning on product. The Journal of Language for International Business, 17(1): 29-42.

4. Chen, S. (2002). The spread of English in Taiwan: Changing uses and shifting attitudes. Taipei, Taiwan: Crane.

5. Cifuentes, L., \& Shih, Y. D. (2001). Teaching and learning online: A collaboration between U.S. and Taiwanese Students. Journal of Research on Computing in Education, 33(4). 456-474.

6. Cuban, L. (1984). How teachers taught: Consistency and change in American classrooms, 1890-1980.

7. Freire, P. (1970). Pedagogy of the oppressed. New York: Herder and Herder.

8. Freire, P. (1985). The politics of education: Culture, power, and liberation. (D. Macedo \& S. Hadley, Trans.). South Hadley, MA: Bergin and Garvey.

9. Hong, Z., Veach, P. M., \& Lawrenz, F. (2003). An investigation of the gender stereotyped thinking of Taiwanese secondary school boys and girls. Sex Roles, 48(11/12), 495-504.

10. Hooks, b. (1989). Talking back: Thinking feminist, thinking black. Boston, MA: South End Press.

11. Jensen, M. (2000). Each year I teach less and less: Confessions of a newly tenured professor. Journal of College Science Teaching, 30(3), 206-207.

12. Lelwica, M. (1999). Liberating learning and deepening understanding: Reflections on feminist pedagogy — as a student, as a teacher. Journal of Women and Religion, 17, 79-85.

13. Madsen, H. S. (1983). Techniques in testing. New York: Oxford University Press.

14. Maher, F. A., \& Tetreault, M. K. T. (1994). The feminist classroom: An inside look at how professors and students are transforming higher education for a diverse society. New York: Basic.

15. McNamara, T. (2000). Language testing. Oxford, UK: Oxford University Press.

16. Presmeg, N. C. (1998). A semiotic analysis of students' own cultural mathematics. Paper presented at the annual meeting of the international group for the Psychology of Mathematics Education, Stellenbosch, South Africa.

17. Rendon, L. (2005). Realizing a transformed pedagogical dreamfield: Recasting agreements for teaching and learning. Spirituality in Higher Education, 2(1), 1-13.

18. Young, R. L., \& Chu, J. W. C. (1993). Balancing the English teaching process in Taiwan. The $10^{\text {th }}$ conference on English teaching and learning in the R.O.C., (pp. 221-230). Taipei: Crane. 


\section{NOTES}

